\title{
EDITORIAL
}

\section{Un sistema de Economía social de mercado para una Europa solidaria, responsable y productiva}

\section{Consejo de Redacción}

Resumen: Este editorial considera el gran paso dado en Lisboa en 2007 para la construcción europea hacia una reconfiguración social y, por tanto, ética del mercado interior en la senda cultural de la mejor tradición del constitucionalismo social de bastantes Estados europeos: el sistema de Economía social de mercado. Como en el siglo pasado se pensó el Estado, a los europeos del siglo XXI nos corresponde ahora pensar el mercado. El establecimiento formal de un sistema socioeconómico con valor normativo, la Economía social de mercado, puede llegar a integrar las aspiraciones más auténticas y elevadas del alma europea: la solidaridad, la responsabilidad y la productividad. Europa sólo podrá salir de su profunda y persistente crisis si no pierde su alma. Esta tarea no la puede hacer sólo un Estado, sino que ha de ser obra de ciudadanos de todos los países europeos. Hemos de acertar en resocializar el proyecto europeo con nuevas energías, con nueva claridad, con nueva pasión europeísta. El editorial parte de un reciente documento de la Comisión de los episcopados católicos de la Unión Europea loctubre de 2011, hecho público en enero de 2012): Una Comunidad europea de solidaridad y de responsabilidad.

Palabras clave: Economía competitiva, Economía social de mercado, Estado social, sistema económico, solidaridad, sostenibilidad, Tratado de Lisboa.

Fecha de aprobación definitiva: 13 de abril de 2012.

La versión del editorial en inglés está disponible en www.revistadefomentosocial.es desde la aparición en papel de este número. Asimismo es libre el acceso a la versión en castellano en la misma dirección. 
For a responsible and productive Europe characterized by solidarity; a social-economic market system

Abstract: This editorial analyses a breakthrough in the design of European integration in favor of social reordering, that took place in Lisbon in 2007. It is, therefore, an analysis of the ethics pertaining to the domestic market, following the best cultural tradition of social constitutionalism of a good part of the European States: the social economic market system. While it was the State that contemplated this issue in the past century, it now corresponds to us, 21 st century Europeans, to reflect upon the market. With the formal establishment of a socioeconomic system with normative capacities, the social economy of the market could lead to the integration of the most authentic and highest aspirations of the European soul: solidarity, responsibility and productivity. Europe can only leave behind its profound and persistent crisis if it manages not to lose its soul. This task is not only Europe's to carry out, but has to be the work of citizens in all European countries. We must succeed in resocialising the European project with new vigor, with new clarity, with a new passion for Europe. The editorial refers to a recent document of the Commission of the Catholic episcopate of the EU (October, 2011, made public in January 2012): A European Community of Solidarity and Responsibility.

Key words: Competitive economy, Social economy of the market, welfare state, economic system, solidarity, sustainability, Treaty of Lisbon.

\section{Pour une Europe solidaire, respon- sable et productive: un système d'économie sociale de marché}

Résumé: Cetéditorial analyse le grand pas, donné à Lisbonne en 2007, vers la conception de la construction européenne vers une reconfiguration sociale et, de ce fait éthique, du marché intérieur sur le sentier culturel de la meilleure tradition du constitutionnalisme social de la plupart des États européens: le système de l'économie sociale de marché. Au siècle dernier, la réflexion s'est centrée sur l'Éłat; c'est à nous maintenant, européens du XXlème siècle, de centrer notre réflexion sur le marché.

La mise en place formelle d'un système socio-économique à valeur normative, l'économie sociale de marché, peut réussir à intégrer les aspirations les plus authentiques etélevées de l'âme européenne: la solidarité, la responsabilité et la productivité. L'Europe ne pourra sortir de cette crise persistante que si elle ne perd pas son âme. Cette tâche ne peut-être réalisée par un seul État; elle doit être l'œuvre des citoyens de tous les pays européens. Nous devons réussir à «ressocialiser» le projet européen avec de nouvelles énergies, avec une nouvelle clarté, avec une nouvelle passion européiste. Cet éditorial a pour point de départ un document récent de la Commission des Épiscopats catholiques de l'Union Européenne (octobre 2011, rendu public en janvier 2012): Une Communauté Européenne de la solidarité et de la responsabilité.

Mots clé: Économie compétitive, économie sociale de marché, État social, système économique, solidarité, durabilité, Traité de Lisbonne. 
Ante los grandes desafíos las respuestas no pueden ser tibias ni de corto alcance. La actual situación europea es tal que sólo con un cambio profundo en la línea de la economía social de mercado (ESM, a partir de ahora) establecida en el llamado Tratado de Lisboa como núcleo definitorio del sistema económico de la Unión Europea (UE, a partir de ahora), podremos salir del actual bloqueo.

En este editorial defendemos el gran avance acaecido en 2007 -aunque en buena parte interrumpido a partir de 2008- hacia una reconfiguración social y ética del mercado interior en la senda cultural de la mejor tradición del constitucionalismo social de buena parte de los Estados miembros, entre ellos España. Este pensamiento constitucional está fuertemente inspirado y enraizado en los principios filosóficos y jurídicos así como en los valores políticos y sociales de la cultura europea. Nos corresponde ahora pensar el mercado desde la fidelidad a nuestro patrimonio cultural y ético y, desde luego, desde el compromiso con el establecimiento formal del sistema socioeconómico de una ESM con valor normativo. Ésta integrará las aspiraciones más auténticas y elevadas del alma europea: la solidaridad, la responsabilidad y la capacidad productiva; al menos sólo ella es capaz de lograrlo. Esta tarea no la puede hacer España aisladamente, sino que ha de conjuntar a todos los ciudadanos y países en el actual marco europeo. Nuestro mensaje implica una renovada confianza en el modelo europeo: j ....más Europa! Hay que resocializar el proyecto europeo de ESM con nuevas energías, con nueva claridad, con nueva pasión europeísta. El día de cierre de este editorial leemos las declaraciones de Enrique Barón, presidente que fue del Parlamento europeo: Europa (es) la única región del mundo donde hay una economía social y un modelo social (...que) como tesoro, hay que defender.' Esta convicción y aquella misión inspiran nuestra reflexión, que esperamos sea compartida por nuestros lectores.

\section{Introducción}

Sólo un cambio profundo en la línea de la economía social de mercado, establecida por el Tratado de la Unión Europea de 2007 (en vigor en 2008), llamado Tratado de Lisboa (TUE), como núcleo definitorio del sistema económico de la UE, nos permitirá salir de la actual crisis europea. El gran avance en el diseño de la construcción de Europa dado en Lisboa fue decisivo.

${ }^{1}$ Declaraciones recogidas por la Agencia Europa Press.

Revista de Fomento Social 67 (20/2) 
Un reciente documento de la Comisión de los episcopados católicos de la UE (COMECE), que fue aprobado en la sesión de octubre de 2011 , aunque no ha sido hecho público sino en enero del presente año 2012, Una Comunidad europea de solidaridad y de responsabilidad. Declaración de los obispos de la COMECE sobre el objetivo de una economía social de mercado competitiva en el Tratado de la UE, manifiesta una notable confianza en el sistema económico institucional sancionado por el TUE y anima a su defensa y difusión. Nuestro punto de partida como comentario ha sido este reciente e importante documento. Se trata de una declaración episcopal sobre el objetivo de una economía social de mercado que sea competitiva en el marco del Tratado de la UE conocido como Tratado de Lisboa.

En la crisis económica actual muchos son los que preferirían una convergencia hacia un único modelo de capitalismo neoliberal que está precisamente en el origen de la crisis. Nosotros, en este comentario, queremos, más bien recuperar y profundizar el sistema económico y social de ESM. ${ }^{2}$

En nuestro comentario, en primer lugar haremos algunas aproximaciones al contexto europeo y mundial en que se sitúa el debate y la defensa del sistema económico propio del Estado social, concebido desde el ámbito de la actual UE, un sistema de ESM que sea a la vez solidario, responsable y productivo. Resumiremos, a continuación, algunas claves del citado documento episcopal. En tercer lugar, deseamos ofrecer algunas reflexiones que ese texto nos ha sugerido: nuestra intención no es otra que la de ayudar a comprender lo que la apuesta por una economía social de mercado altamente competitiva implica, al tiempo que destacamos algunas consecuencias prácticas que se siguen de ello. Proponemos, pues, una reflexión que va más allá del documento, pues queremos compartir con nuestros lectores sugerencias, cuestiones, dudas o desafíos que ha generado en nosotros la lectura del texto. En la conclusión nos pronunciaremos sobre algunos aspectos abiertos. También nosotros queremos que la ESM sea "más europea" y para ello aportamos razones de defensa de un sistema social más equitativo, sostenible y justo.

\footnotetext{
2 Recientemente hemos publicado algunos artículos sobre este tema, como los de Sols, FLORENSA y CAMPRODÓN, en RFS 64 (2009) 79-102, Font 64 (2009) 655-666 y MOYANO 65 (2010) 119-138, así como editoriales sobre diferentes aspectos relacionados con Europa en los volúmenes 47 (1992) 50 (1995), 52 (1997), 54 (1999), 56 (2001), 61 (2006), 63 (2008), 65 (2010) y 66 (2011).
} 


\section{El contexto europeo y mundial}

Con nuestro comentario editorial queremos, en primer lugar, identificar el objeto fundamental de la institución de la economía social de mercado en cuanto sistema económico jurídicamente instaurado por el TUE.

2.1. Una precisión previa es esencial a nuestro propósito. Se trata de la distinción conceptual y práctica entre sistema y modelo. En todo el editorial emplearemos el término conceptual de sistema económico, en vez del de modelo económico cuando nos refiramos a la ESM como institución. Desde esta perspectiva sistemáticoconceptual, una vez institucionalizada jurídicamente la ESM (aún no cabe hablar de "constitucionalización") en el art. 3.3 (TUE), parece conveniente distinguir entre sistema económico de ESM y modelos económicos conformadores de las políticas concretas que, siempre dentro de los límites jurídico-políticos del sistema de ESM, pueden variar en el grado y calidad del compromiso o implicación político-social o en el modo de interpretar la política económica a tenor de las circunstancias políticas, sociales y económicas de cada momento o del signo político de la mayoría del Parlamento europeo, de las autoridades de la Comisión, de los representantes estatales que forman el Consejo europeo, etc.

La UE ha institucionalizado jurídicamente en su Tratado el sistema económico de $E S M$, pero ha dejado un amplio margen a las autoridades europeas para configurar y aplicar modelos plurales y alternativos en las diversas políticas de gobierno (económica, social, monetaria, fiscal, comercial, concurrencial, medioambiental, de seguridad y de inmigración, etc.). Esta posible o admisible diversidad de modelos ha de fundamentar necesariamente su legitimación político-jurídica y ética, así como ajustar sus límites, en el marco del sistema de principios jurídicos, valores normativos y reglas jurídicas particulares institucionalizadas en una unidad de orden jurídico - esto es, en forma de sistema-, para así asegurar las conexiones de sentido entre todos ellos.

En realidad el Tratado de Lisboa ha institucionalizado jurídicamente lo que ya existía de hecho como sistema socioeconómico con valor normativo inspirador de toda la vida económica y social: instituciones, agentes privados y públicos, libertades, derechos, deberes, responsabilidades, procedimientos, etc.

Precisamente, el establecimiento de la "economía social de mercado altamente competitiva" (art.3.3 TUE) como medio o instrumento para que el mercado interior europeo obre en pro del desarrollo sostenible, supone la institucionalización de 
un sistema económico concreto en el que se expresan y aseguran las conexiones de sentido de los principios jurídicos, valores normativos y reglas particulares de la UE. Una vez institucionalizada la ESM "altamente competitiva" en el TUE y, por tanto juridificado lo que en el plano doctrinal y político-social constituía hasta ahora un sistema económico socialmente típico, cabe ya calificar a aquélla como categoría normativa que constitucionaliza un sistema económico-social con valor normativo. De ahí la función sistemático-conceptual y normativa propia del término, ya juridificado, sistema económico asumido en su función ordenadora de toda la vida económica y social (instituciones, agentes privados y públicos, libertades, derechos, deberes, responsabilidades, procedimientos, etc.).

Las ciencias sociales, como la economía, no deben desconocer esta tipificación social y jurídica de lo que normativamente es el sistema económico, debiendo reservar el término conceptual de modelo económico en referencia a las diversas políticas o hipótesis de trabajo, técnicas experimentales con funciones indagatorias o descriptivas (pero no normativas) con que trabajan los economistas. Los gobiernos, como ya hemos señalado, pueden proponer, aplicar y desarrollar diversos modelos económicos y sociales, siempre que estén legitimados por el sistema económico.

\title{
CUADRO I. Estado social y Estado de bienestar
}

\begin{abstract}
Ambos términos se emplean indistintamente, pero no se identifican sin más. El Estado social, originado en la Alemania de finales del siglo XIX y profundizado en la Europa de entreguerras, se configuró por una tendencia expansiva en los "treinta gloriosos", época dorada del capitalismo europeo después de 1945 con un crecimiento ininterrumpido del PIB y pleno empleo, como "Estado de bienestar" (bajo el influjo de pensadores como Keynes o Beveridge) o Estado providencia, con sus cuatros pilares (seguro de enfermedad, invalidez, desempleo y pensiones de vejez). En el Estado de bienestar que surgió tras la segunda guerra mundial, hay que distinguir tres modelos, según Esping-Andersen: conservador, liberal y socialdemócrata. Nuestra Constitución de 1978 define el Estado social en su art. 9.2 como aquel que para garantizar la real y efectiva libertad e igualdad de los ciudadanos, "promueve" las condiciones necesarias, "remueve" obstáculos y "facilita" la participación de los ciudadanos. El Estado social está esencialmente vinculado al Estado democrático de derecho en su actual configuración nacional. Como escribe I. Sotelo, el capitalismo necesita del Estado social para seguir existiendo, hasta el punto de que capitalismo y Estado social se han fusionado en una simbiosis -"economía social de mercado"-de la que los europeos se sienten orgullosos y pocos conciben que en un futuro previsible pueda desaparecer.
\end{abstract}


2.2. En segundo lugar, queremos hacer explícito el significado de Europa solidaria, responsable y productiva. La economía social de mercado como categoría políticosocial y económica caracterizada por los fundamentales principios de solidaridad, responsabilidad y productividad, muestra no sólo lo que ya existe, sino lo que debe ser por imperativo jurídico "constitucional" de los Tratados. Esta triple apelación subyace al título y contenido del documento de la COMECE, objeto de análisis en este editorial: Una Comunidad europea de solidaridad y de responsabilidad. Declaración de los obispos de la COMECE sobre el objetivo de una economía social de mercado competitiva en el Tratado de la UE.

El 13 de diciembre de 2007 fue aprobado por la Cumbre europea el Tratado de Lisboa por el que se modifican el Tratado de la Unión Europea y el Tratado constitutivo de la Comunidad Europea. La ceremonia tuvo lugar en el monasterio de los Jerónimos de Belem, en la capital portuguesa. El título tan complicado que se escogió refleja la solución encontrada a la situación creada tras el fracaso del Tratado constitucional europeo de 2004. Se buscaba con este nuevo tratado sistematizar el largo camino que la Unión Europea ha recorrido en más de medio siglo recogiendo lo esencial de los dos tratados de referencia: el Tratado constitutivo de la Comunidad Europea (Roma 1957) y el Tratado de la Unión Europea (Maastricht 1992).

En este intento de sistematización se modificó el art. 2 del Tratado de Maastricht (que correspondería luego al art. 3 del Tratado de Lisboa). En ese artículo se dice:

La Unión establecerá un mercado interior. Obrará en pro del desarrollo sostenible de Europa basado en un crecimiento económico equilibrado y en la estabilidad de los precios, en una economía social de mercado altamente competitiva, tendente al pleno empleo y al progreso social, y en un nivel elevado de protección y mejora de la calidad del medio ambiente.

Hemos puesto en redonda lo que va a ser objeto de este editorial y lo hemos escogido porque ha sido tratado por el citado documento de los obispos católicos europeos de la COMECE (Comisión de los episcopados de la Comunidad Europea).

El interés de este documento, en el contexto de la formulación del Tratado de Lisboa y de la posterior crisis financiera y económica que embarga a Europa, nos ha decidido a hacerlo objeto de las reflexiones que siguen. Nos proponemos hacer una breve presentación de su contenido, que sirva a nuestros lectores como invitación para conocerlo más directamente. ${ }^{3}$

${ }^{3}$ El texto puede consultarse y "descargarse" en la web de COMECE (Square de Meeûs 19, B-1050 Bruselas, http://www.comece.org). Está disponible la versión original alemana, la francesa y la inglesa. 


\section{El documento sobre la economía social de mercado: algunas claves de lectura ${ }^{4}$}

El documento viene precedido por una carta del presidente de la COMECE, Adrianus van Luyn, obispo de Rotterdam. En ella se expresa el objetivo que se han planteado los obispos al iniciar esta reflexión: dar contenido al término economía social de mercado altamente competitiva. Ésta nos informa también de que el proyecto fue encargado en mayo de 2010 a la Comisión social de la COMECE, presidida por el cardenal Reinhard Marx, arzobispo de Múnich. ${ }^{5}$

Es precisamente R. Marx el que firma la "síntesis" con que se abre el documento. En estas dos páginas y media se recoge muy bien lo esencial del texto: su objetivo, y sus partes. El objetivo que se proponen los obispos es "hacer evolucionar el Mercado común según el concepto de una ESM para que la Unión europea pueda llegar a ser una comunidad viable de solidaridad y de responsabilidad". Después de referirse a los fundamentos culturales de la ESM, pasa a enumerar las cuatro características que definen a este sistema: la importancia de la acción libre y gratuita para la cohesión social, la necesidad de que sea competitiva para liberar recursos suficientes para los gastos corrientes, la política social y la dimensión ecológica.

\section{CUADRO 2. Estructura del documento de la COMECE}

(octubre de 20II)

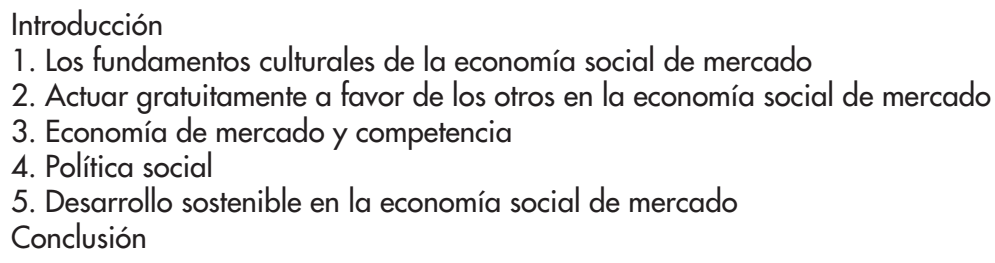

${ }^{4}$ Sobre el documento pueden leerse: É. PeRROT "L'Europe et l'économie sociale de marché" en la web del CÉRAS (París) http://www.ceras-projet.org, así como el editorial debido a G. COSTA, "Un’Unione di mercato e società: la proposta dei vescovi europei": Aggiornamenti Sociali 63 (2012) 181-188.

${ }^{5}$ En la carta de presentación del Presidente de la COMECE se agradece la colaboración prestada por el Instituto Central para la Doctrina Social de la Iglesia de la Conferencia Episcopal Alemana, que organizó en mayo de 2011 en Mönchengladbach una conferencia sobre ética social, que sirvió para la elaboración de este documento. 
Estas cuatro características vienen a constituir la columna vertebral del documento, como se puede constatar a la vista de su división en capítulos.

En efecto, los capítulos 2 a 5 explican el alcance y contenido de esas cuatro características del modelo propuesto para la Unión Europea, procurando descender a algunas propuestas concretas en relación con cada una de ellas, como se dice también en la síntesis inicial.

Veamos brevemente el contenido de cada uno de los capítulos.

Introducción. Ésta es muy breve y se limita a mencionar cómo el Tratado de Lisboa ha introducido la ESM entre otros objetivos. Los obispos europeos han querido destacar este objetivo puesto que es más necesario en el contexto de la crisis actual.

1. Los fundamentos culturales de la economía social de mercado. El concepto de ESM quiere vincular el principio de libre mercado con el principio de solidaridad, la competitividad con la justicia social. Ésta es una opción ética que encuentra su fundamento en la cultura europea y, últimamente, en la visión cristiana de la persona y en la herencia grecorromana.

En efecto, la persona es entendida por la filosofía griega y por el derecho romano como individuo responsable de sí mismo dotado de derechos y deberes. Para la tradición cristiana la dignidad humana procede de un doble principio: ser creado por Dios a su imagen, con una dignidad reforzada por la encarnación de Dios en Jesucristo.

La justicia, que la filosofía antigua contaba entre las virtudes cardinales como dar a cada uno lo suyo, es elevada por la teología cristiana (al afirmar la igual dignidad de todos los seres humanos) y enriquecida por el mandamiento del amor.

2. Actuar gratuitamente a favor de los otros en la economía social de mercado. Se comienza con una breve referencia a la introducción de la ESM en Europa Occidental después de la segunda guerra mundial y en Europa Central y Oriental a partir de 1989.

Este modelo se basa en una doble convicción: que la intervención de los poderes públicos se hace necesaria para complementar el libre mercado, pero que es preciso al mismo tiempo garantizar el espacio para iniciativas privadas movidas por la generosidad. La intervención del Estado garantiza la solidaridad, que se basa en el sistema impositivo, pero esta solidaridad institucionalizada no debe ahogar 
iniciativas de la sociedad (del tipo de las sociedades mutuas, cooperativas o, más recientemente, instituciones y empresas de economía social y de inversión ética); así se armoniza la solidaridad con la subsidiariedad. Los obispos quieren dejar muy claro que no se puede excluir una solidaridad que nazca espontáneamente de la sociedad, aun cuando la ESM remite en primer lugar a responsabilidades públicas.

3. Economía de mercado y competencia. Éste es el capítulo más extenso y el que trata más directamente de la fórmula "ESM altamente competitiva". Se parte para ello de la contradicción que constituye para muchos la unión de competencia de mercado y principio de solidaridad.

La postura de los obispos es muy clara: hay que poner el acento más en la palabra "social" que en lo de "altamente competitiva", porque lo social es el fin mientras que la competencia es el medio.

El conjunto del capítulo insiste en la idea de que el mercado es necesario y positivo, pero debe ser sometido a control. Ni siquiera se puede considerar la competencia como un "fenómeno natural" que deriva espontáneamente de la libertad de mercado. Por eso la verdadera competencia exige una intervención externa al mercado para que quede garantizada.

Por otra parte el Estado tiene que imponer límites al mercado. Que ello es necesario lo ilustra suficientemente la crisis financiera reciente, que exige una regulación de los mercados financieros y el control del comportamiento irresponsable de muchos directivos (con altas retribuciones establecidas desvinculando responsabilidad y riesgo).

Limitar el mercado es todavía necesario por dos razones: si el mercado ha de estar al servicio del ser humano, no reduciendo a éste a simple productor y consumidor, hay que intervenir siempre que su funcionamiento produce daños a la vida y al desarrollo de las personas; pero además hay que impedir que el mercado invada y domine con su lógica todo los dominios de la vida humana.

Más aún, la limitación del mercado no es competencia sólo del Estado, es también responsabilidad de los ciudadanos: y esto exige, sobre todo en sociedades con alto nivel de bienestar, una gran calidad moral a la hora de actuar como consumidores (atendiendo, por ejemplo, a la forma como los bienes han sido producidos y han llegado a nosotros). 
4. Política social. El documento propone avanzar desde la situación actual (en que las políticas sociales son competencia casi exclusiva de los Estados miembros) hacia una mejor distribución de las competencias en este terreno entre la Unión y los Estados.

Por lo demás se vuelve a insistir en la limitación del mercado: en este caso, por su incapacidad para responder a aquellas necesidade humanas que no van acompañadas de capacidad de pago. Tienen aquí su fundamento las prestaciones sociales.

En cuanto a áreas concretas en que las políticas sociales de la Unión Europea deberían avanzar, se mencionan éstas: la promoción del empleo ante el fenómeno del paro masivo con una reducción de las cargas que gravan a la empresa por el empleo del factor trabajo, las políticas de promoción de la familia y las inversiones en educación y, por último, la atención a los trabajadores inmigrantes, necesarios en el futuro.

5. Desarrollo sostenible en la economía social de mercado. Se comienza aquí mencionando el art. 3.3 del TUE, que relaciona el desarrollo social y el desarrollo medioambiental. Y se hace una clara afirmación en favor de una economía sostenible y competitiva, que ponga en juego fuertes dosis de innovación para incrementar la productividad de los recursos. Es preciso hacer una nueva elaboración del concepto de desarrollo, en el que se una la búsqueda de una mayor eficacia de las tecnologías a una revisión de los criterios de consumo.

De nuevo se recuerda aquí la insuficiencia del mercado. El medio ambiente es un bien público que no responde a los mecanismos del mercado. Ello hace imprescindible un compromiso institucional, en este caso europeo y mundial.

Conclusión. La gran tarea pendiente es que ese objetivo -crear una ESM- que se ha dado la UE, se haga realidad en el espacio europeo y no sólo en el de los Estados miembros. La crisis sobrevenida posteriormente no ha hecho más que dejar en evidencia la interdependencia de nuestro mundo.

En concreto la UE tiene una responsabilidad muy destacada en el desarrollo a largo plazo de una "auténtica autoridad política mundial", siguiendo la propuesta de Benedicto XVI en su encíclica Caritas in veritate (2009).

El texto concluye recordando que el proyecto de integración europea era, desde el comienzo, no solo económico sino también político y moral y estaba al servicio de la justicia y de la paz en Europa y en el mundo entero. 


\section{CUADRO 3. Características de la economía social de mercado}

1. La ESM ha de promover la cohesión social, dotándola de un marco jurídico compatible con su especificidad social y económica.

2. La ESM debe ser económicamente competitiva, capaz de sanear y aligerar los impuestos y de reducir la deuda y los gastos.

3. La política social de la ESM se expresa a través de la protección social y la justicia participativa para todos los necesitados conforme a los principios de solidaridad y subsidiariedad.

4. La ESM debe ser ecológicamente sostenible. Una cultura de la "moderación" es condición para una gestión sostenible de los recursos naturales y para la lucha contra las consecuencias del cambio climático.

\section{Reflexionando más allá del documento}

El resumen que precede, y sobre todo la lectura del texto completo, no habrá dejado indiferente al lector. Son muchas las cuestiones que suscita. En esa línea se mueve esta tercera parte de nuestro editorial: compartir con nuestros lectores sugerencias, cuestiones, dudas o desafíos que ha generado en nosotros la lectura del texto.

\section{I.Aspectos más destacables en el texto}

El documento no se mueve exclusivamente en terreno de los grandes principios, sino que contiene muchas propuestas concretas, como señala R. Marx en la síntesis introductoria, de entre las que destacamos: la protección social y la justicia participativa para todos; una economía ecológicamente sostenible; la defensa de esta política por la Unión Europea en los foros internacionales; una atención especial a las mutualidades, a las cooperativas, a otras formas de economía social y a la inversión ética; una particular atención a la supervisión del sector financiero; la promoción de un consumo responsable; un trabajo conjunto de los países de origen y destino para gestionar de forma regulada los flujos migratorios; un proceso gradual de desarrollo de una auténtica autoridad política mundial, etc.

Más allá de estas propuestas concretas, nos permitimos subrayar algunos puntos que nos han parecido más significativos: 
a) Es preocupación de los obispos poner de relieve la dimensión ética de la propuesta global de ESM altamente competitiva. Este sistema de organización socioeconómica se justifica no solo por razones históricas o políticas, sino por los valores éticos en que se apoya, y que están identificados desde el título mismo que se ha escogido: la solidaridad y la responsabilidad. Las referencias a ambos valores a lo largo del documento son continuas.

b) El acento se pone más en la ESM que en lo de "altamente competitiva". No sólo se dice rotundamente al comienzo del capítulo 3: mercado y competencia son medios, lo social es el fin (n.6). Y se repite más adelante insistiendo en que el mercado es un medio al servicio de la persona, y que ésta no puede ser reducida a ser un productor y consumidor, es decir, un agente del mercado (n. 10). ¿ Se puede ver aquí un correctivo o crítica a la propuesta global de Tratado de Lisboa de "ESM altamente competitiva", exigiendo que se matice mejor la relación entre esos dos elementos unidos por la fórmula analizada?

c) Las referencias a las limitaciones del mercado son también continuas, aunque se reconozcan las ventajas del mismo. Pero la insistencia está más en destacar su insuficiencia para un funcionamiento aceptable de la economía. Estas limitaciones deben ser subsanadas o contrarrestadas, lo que es competencia del Estado en primer lugar, aunque también -volveremos sobre este punto- de los órganos de la UE, sin relegar a un último lugar el papel de los ciudadanos. Esta referencia a la responsabilidad de los ciudadanos nos parece de especial interés, para no caer en la tentación, tan frecuente, de encomendar toda la responsabilidad sobre los intereses generales de la sociedad al Estado.

En todo caso, hay que anotar que el documento da un relieve a esta cuestión muy superior al que posee en el mismo texto del Tratado.

\section{CUADRO 4. Texto del Tratado de Lisboa que modifica el artículo segundo del TUE ${ }^{\circ}$}

1. La Unión tiene como finalidad promover la paz, sus valores y el bienestar de sus pueblos.

2. La Unión ofrecerá a sus ciudadanos un espacio de libertad, seguridad y justicia sin fronteras interiores, en el que esté garantizada la libre circulación de personas con-

\footnotetext{
${ }^{6}$ Versión consolidada del tratado de la Unión Europea, $\operatorname{art}^{\circ} 3$ (antiguo artículo 2 TUE). Cfr. Diario
} Oficial de la Unión Europea, 30 de marzo de 2010, C 83/17. 
juntamente con medidas adecuadas en materia de control de las fronteras exteriores, asilo, inmigración y de prevención y lucha contra la delincuencia.

3. La Unión establecerá un mercado interior. Obrará en pro del desarrollo sostenible de Europa basado en un crecimiento económico equilibrado y en la estabilidad de los precios, en una economía social de mercado altamente competitiva, tendente al pleno empleo y al progreso social, y en un nivel elevado de protección y mejora de la calidad del medio ambiente. Asimismo, promoverá el progreso científico y técnico.

La Unión combatirá la exclusión social y la discriminación y fomentará la justicia y la protección sociales, la igualdad entre mujeres y hombres, la solidaridad entre las generaciones y la protección de los derechos del niño.

La Unión fomentará la cohesión económica, social y territorial y la solidaridad entre los Estados miembros.

La Unión respetará la riqueza de su diversidad cultural y lingüística y velará por la conservación y el desarrollo del patrimonio cultural europeo (... siguen apartados 4, 5 y 6).

Como se puede comprobar, el Tratado de Lisboa no establece una clara jerarquía de sus objetivos. ¿̇No hubiera sido deseable una formulación más rigurosa de los objetivos que presiden todo el proceso de integración europea? Los obispos parecen estar sugiriendo -con buen criterio, sin duda- que a la "ESM altamente competitiva" debería reconocérsele una prioridad especial.

\subsection{Un sistema de economía social de mercado que quiere ser "altamente competitivo"}

La fusión de estos dos elementos -social y competitiva- no es evidente ni está exenta de dificultades. Los mismos obispos dan por supuestas esas dificultades cuando priorizan un elemento sobre el otro, el que es fin sobre el que es medio.

De las dificultades de la fórmula es un buen exponente el origen mismo de la expresión ESM. Empezó a utilizarse después de la segunda guerra mundial y con ella se pretendía una alternativa al modelo capitalista liberal, que no se confundiese con la economía planificada soviética. La ESM tuvo vocación de "tercera vía" y así la concibió el primero que empleó esa fórmula, el economista Alfred MüllerArmack, quien no quería abandonar los principios de la economía de mercado, pero buscaba corregir sus excesos con una intervención del Estado, y que abogaba por la libre formación de precios en el mercado, aunque preveía la existencia de controles en los sectores menos competitivos como la agricultura o la energía y propugnaba medidas activas de política económica conducentes a la consecución 
del pleno empleo y redistribución de la riqueza. Müller-Armack mostraba una preocupación especial por la estabilidad de precios, por lo que era partidario del equilibrio presupuestario, aun a costa del otro gran objetivo como el pleno empleo, en lo que tomaba cierta distancia de la ortodoxia keynesiana.

\section{CUADRO 5. Orígenes de la economía social de mercado}

La economía social de mercado(ESM) es aquella forma de economía mixta de mercado que incluye los puntos de vista o criterios sociales en la promoción básica de la competencia, organizando la economía nacional a partir de la coexistencia y complementariedad de una regulación de mercado y una intervención activa del Estado en la esfera productiva.7

La cuna intelectual de la ESM fue la Escuela del Ordoliberalismus, que había fundado el profesor W. Eucken, catedrático en la Universidad de Friburgo de Brisgovia de 1927 a 1950; en ella tuvieron un papel destacado el jurista más acreditado de esa escuela, Franz Böhm, el economista Alfred Müller-Armack y el sucesor como canciller de Konrad Adenaver, Ludwig Erhard.

El sistema doctrinal de la ESM surgió en los años treinta del siglo XX. Dicha escuela y su doctrina se enmarcaban en el largo y denso debate constitucional acerca del significado y contenido del Estado democrático de derecho consagrado en la Constitución de Weimar. El debate se centró en la forma y funciones del Estado constitucional, fundamentalmente en lo concerniente a su dimensión social y su implicación con la economía. El núcleo de la discusión radicaba en el surgimiento de un nuevo modelo de Estado social fruto de la fuerte implicación de la Constitución y la economía, dando así lugar a la génesis de nuevo concepto de extraordinaria importancia en Europa: la constitución económica (Wirtchaftiverfassung).

En ese momento ya se confrontaron dos posiciones: una, socialdemócrata, que propugnaba un nuevo modelo Estado de carácter social; y otra, liberal, que al asumir su tradición histórica aportaba como novedad histórica la intervención pública o estatal en la economía de mercado como instrumento de corrección y de garantía del funcionamiento del sistema de economía de mercado.

Este debate típicamente "weimariano" se prolongó en las constituciones europeas de la segunda postguerra, contexto donde cobró protagonismo la escuela de Friburgo, que partió de la recuperación del antedicho debate "weimariano" acerca de la constitución económica entendida como "decisión global sobre el ordenamiento de la vida económica de una comunidad" (Böhm). Los autores citados de la Escuela de Friburgo comenzaron por reconocer como sistema normativo de referencia la economía de mercado, dentro del cual debían encontrar su sentido las normas del ordenamiento que regulan la economía,

${ }^{7}$ Dos monografías fundamentales pueden ser útiles para este debate: Juan lgnacio FONT GALÁN (1987) Constitución económica y derecho de la competencia, Madrid, Tecnos, pp. 131-165, e lgnacio SOTELO (2010) El Estado social: antecedentes, origen, desarrollo y declive, Madrid, Trotta, 425 pp. 
aunque introdujeron una importante novedad, frente al sistema de economía liberal heredado del siglo XIX: el reconocimiento de una función reguladora del Estado en la actividad económica general, que no se trataba de una función interventora o centralizada de la economía, esto es, de corte dirigista o vinculante, sino sólo de una función reguladora del funcionamiento eficiente del mercado.

Esta función proactiva del Estado suponía reconocer de un lado que el mercado ya no se regía por su orden natural, ajeno o refractario a toda regulación externa o estatal, y de otro que el Estado tenía como propia una indeclinable función pública de ordenación de la economía.

El "ordoliberalismo" -o liberalismo regulado- proponía que la economía de mercado se rigiese por las reglas naturales de la libre competencia, aunque bajo el directo control y regulación del Estado, sin el cual ésta se autodestruye y, con ésta, se garantizaban la libertad y la igualdad en el mercado. Corresponde a Müller-Armack la autoría de la expresión ESM, con la que propugnaba la compatibilización de tres elementos: la regulación estatal del mercado como garantía de la competencia, la intervención social (la política social) y la intervención pública de coyuntura. Un axioma de la ESM es que "el mercado requiere Estado", por lo que éste debe limitarse a establecer las "reglas del juego" de los operadores económicos, públicos, sociales y privados, sin concretar rígidamente fines, funciones ni contenidos de la política económica. Por ello, los teóricos de la ESM reivindican frente al Estado liberal y su derecho inhibicionista, un Estado que asume como propia la misión de regular la economía de mercado (N. Reich), que se corresponde al Estado cooperador como Estado social.

A partir de 1949 la expresión se incorporó al programa electoral del partido demócratacristiano, los llamados axiomas de Düsseldorf. Para algunos democristianos como para grupos socialdemócratas y sindicatos, la expresión podía ser algo simplemente propagandista, pero los grupos empresariales y los liberales temían que el atributo social despertara esperanzas que estuvieran en contra de la competitividad. Más adelante la ESM terminó inspirando también las políticas de la socialdemocracia, aunque con algunos matices diferentes, por lo que puede considerarse como el paradigma inspirador del "milagro alemán" que sirvió a la reconstrucción de un país que estaba literalmente arrasado al concluir la guerra. Algunos de sus rasgos más característicos, como la atención a la estabilidad de precios y del gasto, deja sentir todavía hoy su influjo en la UE a través del gobierno alemán.

Esta doctrina ha tenido gran influencia en toda Europa si bien con versiones diferentes, adaptada a los condicionantes constitucionales de cada país. Aunque esta expresión se utiliza principalmente en países de habla alemana, está también presente en la tradición constitucional de otros como Polonia. En España, el Tribunal constitucional la reconoce como propia y definitoria de nuestra constitución económica.

El documento de la COMECE, sin negar la paternidad germana a la ESM, quiere descubrir sus raíces mucho más lejos: en toda la tradición cristiana y occidental, que incluye la filosofía griega y el derecho romano. Toda esa herencia histórica ha contribuido a perfilar una visión de la persona y una concepción de la justicia 
que son los pilares sobre los que se levanta posteriormente la ESM: la dignidad de la persona humana exige que el sistema económico esté a su servicio; la justicia lleva a la afirmación de la igualdad de todos los seres humanos y, gracias al precepto cristiano del amor, a una atención especial a los más necesitados. Estos son los fundamentos que justifican la responsabilidad del Estado para corregir las limitaciones del mercado y su dificultad para reconocer en la práctica la prioridad de la persona, así como las políticas sociales tendentes a garantizar una igualdad básica de todos los ciudadanos y a corregir las desigualdades que el sistema produzca. Todo el capítulo primero del documento desarrolla estas ideas, a las que luego alude el texto en diferentes ocasiones.

Hasta aquí lo que se refiere a la ESM. Ahora bien, ¿̇cómo armonizar eso con la exigencia de que además ésta sea "altamente competitiva"? Ése es el gran reto del momento actual, que se puede aclarar volviendo la mirada al pasado histórico. Porque la ESM fue una de las fórmulas que se encontraron para salir de la grave situación a que había conducido un capitalismo de libre mercado puro, vigente durante todo el siglo XIX y con serios avisos de crisis irreversibles en el primer tercio del siglo XX. Todas las respuestas que se dieron para superar definitivamente esa crisis, excluyendo la alternativa del colectivismo de planificación central, tomaron la senda de un sistema mixto donde mercado y poderes públicos se articularon de forma equilibrada para garantizar eficiencia económica y equidad social. Distintos fueron los modelos resultantes, todos ellos basados en lo que se llamó en su momento el "consenso socialdemócrata", una especie de convergencia fáctica entre el catolicismo social ampliamente arraigado en Europa antes de 1945, las tendencias liberales sociales, que cedían en algunos aspectos, reconociendo las disfunciones que había producido el modelo inspirado exclusivamente por ellas, y las socialdemócratas, incluso socialistas, que encontraron en esa inviabilidad del capitalismo liberal la oportunidad para hacer su aportación específica.

Pero en la historia nunca se llega a situaciones de equilibrio definitivo. Y hoy parece que asistimos a un giro en esa evolución. La ESM y otros modelos semejantes, todos ellos formas de capitalismo mixto, atraviesan por serias dificultades por causas externas, entre las que suele citarse el contexto de una economía crecientemente globalizada aunque también por causas internas, por ciertas disfunciones que el propio sistema ha creado. El tema sería largo de analizar. ${ }^{8}$ Pero cabría indicar que la presión ejercida sobre los Estados para que aumenten sus prestaciones sociales y

${ }^{8}$ En los últimos años nuestra revista ha dedicado sendos editoriales a temas relacionados con éste. Cf. RFS 50 (1995) 149-169, "Crisis y futuro del Estado del bienestar" y 54 (1999) 289-308, "¿Es posible la «tercera vía»?". 
sus funciones públicas ha llegado a extremos insostenibles, agravados por el hecho de que la cultura más individualista y pragmática que parece imponerse debilita el apoyo de la sociedad a estas tareas públicas y cuestiona su legitimidad.

Todo eso se agrava por la fuerte presión de la competencia mundial, que actúa de forma cada vez más drástica en el contexto de la globalización. Recuperar la competitividad es casi la condición para que la ESM se mantenga: porque sólo una economía competitiva produce renta para que los Estados puedan ejercer las funciones que se le exigen?. Pero esta es la gran cuestión en la que el documento apenas entra: ¿es posible mantener la ESM tal cual y hacerla a la vez altamente competitiva? La experiencia histórica no es evidente al respecto. Habría que preguntarse qué precio en términos de todo lo que significa la ESM estaríamos dispuestos a pagar por ser "altamente competitivos". Si reconocemos que el sistema se nos ha desequilibrado y la pérdida de competitividad llega a poner en peligro la continuidad de la ESM, lo que urge es plantear los términos de un nuevo equilibrio. Habrá que identificar los logros de la ESM a los que no deberíamos nunca renunciar, discutiendo sobre todo cómo se distribuye la carga del reequilibrio entre los distintos colectivos sociales, territoriales o estatales. El documento de la COMECE es, más bien, una invitación a seguir pensando en esta dirección.

Para proseguir esta tarea no estará de más -eso sí lo hace el documento- insistir en los valores morales que sustentan el sistema: la solidaridad y la responsabilidad, unidos a la productividad. Todo ello exige cuestionar la deriva individualista de nuestra sociedad, donde encuentra poco eco cualquier llamada a sentirnos responsables del interés general $o$, dicho en términos éticos, del bien común social.

\section{CUADRO 6. La Economía social de mercado: una perspectiva jurídica}

La compleja formulación de un sistema de economía social de mercado altamente compe-
titivo exige una ardua tarea de interpretación de los textos jurídicos que la consagran y los
documentos comunitarios que lo desarrollan. La Comisión europea se ha pronunciado am-
pliamente sobre el significado de este sistema económico acompañando además un conjunto
de cincuenta medidas para su desarrollo. En su comunicación "Hacia un Acta del Mercado
Único. Por una economía social de mercado altamente competitiva", de 27 de octubre de
2010, la Comisión europea ha declarado que todas las políticas del mercado único están al
servicio de una "economía social de mercado", para reimpulsar una integración inacabada

${ }^{9}$ Así parece insinuarlo el documento en su síntesis inicial, cuando afirma que la ESM debe ser productiva y competitiva si quiere establecer impuestos y gravámenes para reducir la deuda y financiar los gastos corrientes. 
y convertirla en nuestro potencial de crecimiento al servicio del progreso humano; para recuperar la confianza, todos juntos, en nuestro modelo de economía social de mercado, situando nuevamente a los europeos en el corazón del mercado; y para proponer un nuevo planteamiento global del mercado que considere a todos los agentes del mismo (....). El mercado único no es, en sí mismo un objetivo, sino un instrumento al servicio de las demás políticas (....). Es importante tener presente que el éxito del modelo europeo radica en su capacidad para conjugar rendimiento económico y justicia social. Por su parte, el Comité Económico y Social Europeo en su dictamen sobre la economía social de mercado altamente competitiva de 15 de marzo de 2011, advierte que la UE debe ser capaz de responder adecuadamente a los retos de un mundo globalizado sobre la base de los valores que han caracterizado hasta ahora nuestras economía sociales de mercado basadas en un equilibrio entre las libertades económicas y el respeto a los derechos sociales y sindicales.

Ambos documentos arrojan una apreciable luz para interpretar jurídicamente la enigmática fórmula de la "economía social de mercado altamente competitiva" del art.3.3 TUE. Se trata de una formulación normativa compleja, de carácter pacticio, jalonada por dos principios inicialmente contrapuestos, a saber, el de socialidad (o cláusula social) y el de competitividad (cláusula de productividad). Ambos principios cumplen la función normativa de establecer, uno respecto del otro, límites y contenidos.

Significa esto que las políticas de fomento y defensa de la competitividad o productividad de la economía de mercado no pueden asfixiar las políticas sociales; como tampoco, a la inversa, las políticas sociales no pueden mermar las de fomento de la competitividad. Pero no se trata simplemente de una cuestión de límites y de equilibrios entre principios enfrentados y políticas contrapuestas, sino también, más ambiciosamente, de una exigencia normativa de integración recíproca de los fines y contenidos de ambos principios y ambas políticas: las políticas sociales deben asumir e integrar como propios los fines y contenidos de las políticas de competitividad $y$, a la inversa, las de competitividad deben asumir e integrar como propios los fines y contenidos de carácter social.

Ahora bien, la integración política y normativa de sendos principios contrapuestos, socialidad y competitividad, llamados a conciliarse, sólo será posible si se dan las condiciones de base para que la democracia política y económica sancione y garantice ese hermanamiento ético y político entre la competitividad económica y la justicia social. Sin democracia política y económica la construcción de Europa y de su sistema económico será mera retórica, alimentando así el escándalo y la decepción de la ciudadanía europea. Hoy por hoy, ésta es la mayor debilidad de una ESM altamente competitiva, tan huérfana de democracia y tan desajustada socialmente.

\subsection{De los Estados miembros a la Unión Europea}

Los obispos dan en su documento un salto considerable: pretenden que lo que fue un sistema aplicado, y con éxito, en muchos países sea ahora el sistema de la UE como realidad supraestatal. Es más, ven en ese sistema una ayuda para avanzar en la integración europea. 
Efectivamente la propuesta del Tratado de Lisboa se refiere a la UE. Pero el mismo documento reconoce que las políticas sociales siguen siendo en gran parte competencia de los Estados miembros (n. 13). Aunque las políticas sociales no son la única manifestación de la ESM, no cabe duda que constituyen un instrumento fundamental para que la solidaridad sea realidad en la UE. Se citan otras áreas de intervención; concretamente se pide un derecho contractual europeo que evite algunos cuellos de botella que se están dando en el mercado interior europeo ( $\mathrm{n}$. 20).

Sin embargo, la mayoría de las recomendaciones que contiene el documento se refieren en primer lugar a los Estados miembros. En este sentido se cuestiona la actual orientación de muchos gobiernos de la Unión que, como consecuencia de la evolución demográfica y del desafío que supone la mundialización, están reduciendo sus políticas sociales (n. 15).

No se subraya, en cambio, suficientemente que el gran reto que implica la definición del artículo del TUE que estamos comentando, consiste en hacer avanzar a la UE en la dirección de un cuerpo político cada vez más integrado. Es cierto que se recuerda que el proyecto europeo nunca se limitó a una zona de libre comercio, sino que fue pensado desde el comienzo como una comunidad política y como una comunidad de valores (n. 13), como un proyecto al servicio de la justicia y de la paz en Europa y en el mundo entero (n. 26).

Precisamente el documento comienza el capítulo conclusivo recordando que la Unión Europea se ha dado como objetivo crear una economía social de mercado (n. 24). ¿̇No es una afirmación demasiado fuerte a la vista de lo que dice el Tratado de Lisboa? En él se enumera este objetivo entre otros y no con un relieve especial; pero además se matiza con el añadido de "altamente competitiva", que los obispos dejan sistemáticamente en un segundo plano.

Esto no significa que no estemos de acuerdo con que la UE debe avanzar en esa dirección, no sólo porque lo dice el Tratado de Lisboa, sino porque es un sistema que tiene un profundo arraigo en la tradición cultural del continente y cuenta con una legitimación moral indudable, aunque tememos que, en este momento, este avance no sea fácil. 


\section{CUADRO 7. El futuro del Estado social}

Los cambios que impone la globalización en las instituciones y en la sociedad inciden directamente sobre la política social que continúa siendo competencia exclusiva de un Estado que se ha visto despojado de algunas de sus competencias económicas básicas, lo que hace que los modelos establecidos de política social a medio plazo sean insostenibles (...) parece existir un amplio consenso: el Estado social, tal como lo conocemos, no logrará sobrevivir mucho. (...) seguimos sin saber cuál será la evolución de la crisis, y sobre todo, qué aspecto tendrá el mundo a su salida. Para ser más conscientemente escépticos, libres de falsas ilusiones, conviene repasar las muchas noticias que en los años treinta del siglo pasado anunciaban la pronta salida del túnel, hasta que el estallido de la guerra en septiembre de 1939 transformó la crisis en una tragedia de dimensiones planetarias. Sin la confrontación que marcó aquel decenio entre el capitalismo, remodelado por el fascismo, y el "colectivismo estatalista", nada indica que ahora pudiera ocurrir algo parecido (...), el mundo con el que antes o después nos encontraremos, será muy distinto del actual. Entre los enormes cambios que nos esperan habrá que contar con los que sufrirá el Estado social. ${ }^{10}$

\subsection{El contexto actual no es ya exactamente el mismo del Tratado de Lisboa}

El Tratado de Lisboa se firmó en diciembre de 2007. Aunque la crisis ya había estallado en el sector financiero al menos, sus efectos no eran todavía perceptibles. Ni probablemente era posible en aquellos momentos prever lo que estamos viviendo más de cuatro años después de su aprobación.

Los obispos han pensado el documento con el horizonte de una crisis ya bien instalada y confían en que, para salir de ella, la ESM es el sistema económico necesario y oportuno que hay que promover:

Solidarios y responsables, es así como nosotros, europeos, podremos dominar la grave crisis actual y continuar juntos nuestro camino para dar finalmente un signo eficaz de justicia y de paz a la humanidad entera (n. 24).

Pero no se puede ignorar que la crisis tiene esa doble virtualidad. Por una parte, desata los intereses particulares, en este caso de los Estados miembros. Nunca la UE avanzó en momentos de crisis económica; lo hizo en momentos de expansión. Sin embargo, el grado de integración a que hemos llegado, sobre todo como consecuen-

${ }^{10}$ Cf. I. Sotelo (2010) El Estado social: antecedentes, origen, desarrollo y declive, Madrid, Trotta, p. 396. 
cia de la moneda única, hace más necesario que nunca actuar coordinadamente: si no se hace así, la salida se vislumbra mucho más incierta. Esa es la paradoja: tanto más necesaria cuanto menos se da la predisposición a colaborar.

\section{CUADRO 8. Democracia y futuro de la economía mundial"}

¿Cómo gestionamos la tensión entre una democracia nacional y los mercados globales? Existen tres posibilidades: (a) limitar la democracia con el propósito de minimizar los costes de transacción internacionales, sin tener en cuenta los trastornos económicos y sociales que la economía global produce en ocasiones; (b) limitar la globalización con la esperanza de reforzar la legitimidad democrática en el país; (c) globalizar la democracia a costa de la soberanía nacional, pero no podemos tener hiperglobalización, democracia y autodeterminación nacional todo a la vez.

Si queremos hiperglobalización y democracia, tenemos que renunciar a la nación-Estado; si hemos de mantener la nación-Estado y también queremos hiperglobalización, tendremos que olvidarnos de la democracia; y si queremos combinar democracia con nación-Estado, adiós a una globalización profunda. Ésta es precisamente, según Rodrik, "la paradoja de la globalización".

Por ahora una gobernanza global democrática es sencillamente imposible. Un mundo con una globalización moderada, según Rodrik (op. cit, p. 258) sería un lugar mucho mejor para vivir, que uno atrapado en la quimérica búsqueda de la hiperglobalización (p. 258), aunque muy significativamente la única posible excepción en nuestro mundo, "que confirma la regla", es, según este autor, la UE (p. 257).

Trilema político de la economía mundial

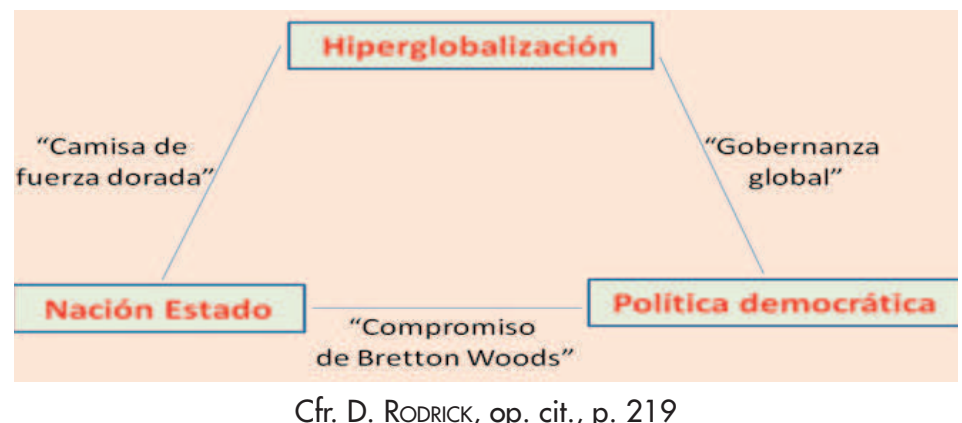

Cfr. D. RODRICK, op. cit., p. 219

"El texto está basado en un reciente estudio del economista norteamericano y profesor en la Kennedy School of Government, de la Universidad de Harvard, D. RODRIK (2012) La paradoja de la globalización. Democracia y el futuro de la economía mundial, Barcelona, Antoni Bosch. 


\section{Conclusión}

Hasta aquí, nuestras reflexiones. Los obispos europeos han hecho un esfuerzo por impulsar el proceso de integración, desde la misión de la lglesia de mantenerse en el terreno de los valores morales que están detrás de las estructuras, las instituciones y los modelos, con un enfoque positivo de propuesta y reduciendo las críticas a una consecuencia de esa propuesta misma.

El documento es una clara apuesta por la ESM como el corazón del sistema económico que se ha desarrollado en Europa continental desde la segunda guerra mundial con resultados indiscutibles. Pero a eso se añade la exigencia de avanzar en productividad y en competitividad. Es cierto que hoy no faltan las dificultades para tamaña empresa. Provienen de una doble circunstancia: no es lo mismo la ESM en los Estados miembros que en la Unión; la crisis hace más dura la transformación y las resistencias hacia un modelo más solidario aumentan.

Hay que ver si la crisis no nos va a obligar a ser más solidarios. Las exigencias del contexto reforzarían las razones éticas para profundizar en la ESM. Si fuera así, ojalá se avanzase con optimismo y no con el sentimiento de que se trata de una imposición inevitable. Para ello es necesario socializar el sistema, es decir hacerlo llegar a la ciudadanía, de manera que llegue a comprender su sentido y su funcionamiento, lo que podríamos llamar la "gramática europea". Ésta, en el proceso de construcción de Europa, ha conjugado siempre el pragmatismo con el idealismo, el más radical pragmatismo realista -primero, la unión económica-, con la afirmación de elevados ideales movilizadores -paz y justicia.

En nuestra conclusión nos vamos a permitir también cuatro notas para pensar esta "hora" de Europa:

A. A lo largo de este editorial, así como en el documento de COMECE que hemos presentado, se han ido exponiendo diferentes propuestas en el marco de la ESM en Europa: la protección social y la justicia participativa para todos; una economía ecológicamente sostenible; la defensa de esta política por la UE en los foros internacionales; una atención especial a las mutualidades, cooperativas, otras formas de economía social y la inversión ética; una particular atención a la supervisión del sector financiero; la promoción de un consumo responsable; un trabajo conjunto de los países de origen y destino para gestionar de forma regulada los flujos migratorios; un proceso gradual de desarrollo de una auténtica autoridad política mundial, etc. Todo esto tiene un origen en los principios que inspiraron el Tratado de Roma y otros posteriores. En estos momentos, sin embargo, es difícil llevar adelante estas propuestas por varias razones: los orga- 
nismos internacionales no han sido capaces de aprobar reformas de calado del sistema (piénsese en lo poco que se ha avanzado en la supervisión bancaria), los mercados financieros siguen dominados por la especulación y por las agencias de valoración ("rating"), en la UE, los gobiernos han vuelto a defender los intereses de sus países por encima del interés comunitario y ello ha ido unido al resurgimiento de "sentimientos" xenófobos y movimientos de extrema derecha. En resumen, no es un buen momento para avanzar (o no retroceder) en la ESM, pero ello no debe impedir que la defendamos como el futuro de Europa, el único que consideramos posible si queremos que la UE tenga, repetimos, futuro.

B. Por el Tratado de Lisboa la UE se fijó el objetivo de la ESM, que hasta entonces ya había demostrado su validez en muchos Estados miembros, aunque hoy hay que dar un paso más, contribuyendo a "un mundo mejor": europeizar la ESM para hacer frente a la competencia global, proporcionando una protección social efectiva a los débiles y logrando una economía sostenible a la luz de las preocupaciones ambientales y climáticas. Para dar vida a la ESM en la Unión Europea necesitamos una comunidad de solidaridad y responsabilidad. Solidarios y responsables, así es como nosotros, los europeos podremos responder a la crisis actual y finalmente ofrecer en nuestro viaje común un signo eficaz de la justicia y la paz a todas las personas en todo el mundo. Como comunidad de solidaridad y responsabilidad la UE no puede reducirse al interior de sus fronteras, sino que ha de servir como "contribución de un mundo mejor", según Jean Monnet; y para ello, para sostener y explicar este proyecto, hay que europeizar de nuevo los grandes fundamentos de aquél, pues hay una generación para la que las razones fundacionales son desconocidas o ya no valen.

C. La crisis económica y de los mercados financieros mostró que los principales desafíos y peligros de la interdependencia de las economías nacionales deben abordarse en el ámbito internacional. La UE, como comunidad de Estados prósperos e industrializados, tiene una responsabilidad moral especial ante las instituciones supranacionales en el desarrollo a largo plazo de una auténtica autoridad política mundial, que debería estar regulada siguiendo los principios de subsidiariedad y solidaridad y ser expresión de un acuerdo libre y compartido y no el resultado de la coerción o de la violencia. Una autoridad política mundial debe ser el resultado de un proceso gradual de maduración de la libertad y de la responsabilidad cada vez mayor, asumida por los pueblos. ${ }^{12}$

12 PONTIFICIO CONSEJO JustiCIA Y PAZ (2011) "Para una reforma del sistema financiero y monetario internacional en la perspectiva de una autoridad pública con competencia universal": RFS 67 (2012) 753-771. 
D. Esperamos haber contribuido a iluminar los fundamentos, significados, objetivos, funciones, exigencias, códigos de conducta ética, contenidos del sistema de ESM: es importante y estimulante porque Europa debe avanzar en la definición explícita y desarrollada de su sistema económico, sólidamente fundamentado. Mantener la actual vacilación o ambigüedad pudiera ser una de las causas del modo de proceder de la UE en la resolución de la crisis actual o de su incapacidad para afrontarla y ofrecer respuestas de largo aliento. La falta de regulación de los mercados financieros, interpretada generalizadamente como una de las razones principales propiciadoras y responsables de la crisis actual, tiene como causa la indefinición de un sistema económico para la UE. El avance definitorio que ha supuesto el Tratado de Lisboa responde -ya anticipada y quizás premonitoriamente- a este diagnóstico. Pero no basta la mera formulación formal y solemne de la ESM como sistema económico de la UE, pues está pendiente su vertebración material en las políticas europeas y en la reglamentación de las mismas, de conformidad con aquella consagración normativa en el TUE. La necesidad de acompañar este proceso de juridificación de la ESM con un rico y sólido pensamiento filosófico, político y social centrado en dotar a este sistema económico y social de un "corpus" doctrinal capaz de iluminarlo es necesaria y urgente. El pensamiento acerca de la ESM es todavía, en buena medida, una tarea pendiente.

Queremos referirnos finalmente a la tradición cristiana de la ESM, que los obispos católicos europeos destacan con satisfacción. Desearíamos que ese patrimonio fuera asumido por los muchos cristianos que viven en Europa. A la Iglesia institucionalmente no le corresponde ofrecer medidas de política económica, ni apoyar o rechazar sistemas económicos específicos, concretas, pero los que alimentan su vida con la fe cristiana sí tienen una responsabilidad de buscar fórmulas concretas para hacer frente a la tarea de la construcción de Europa. No olvidemos que fueron cristianos convencidos los que estuvieron en el origen de todo el proceso de integración europea. También en esta hora de Europa, entre y junto a los pensadores de reflexión profunda, deben estar los cristianos comprometidos con el pensamiento y en la acción, pues, como escribió Pablo VI en 1971,

las organizaciones cristianas (...) tienen que expresar, a su manera y por encima de sus particularidades propias, las exigencias concretas de la fe cristiana para una transformación justa y, por consiguiente, necesaria de la sociedad. Hoy más que nunca, la Palabra de Dios no podrá ser proclamada ni escuchada si no va acompañada del testimonio de la potencia del Espíritu Santo, operante en la acción de los cristianos al servicio de sus hermanos, en los puntos donde se juegan éstos su existencia y su porvenir. ${ }^{13}$

13 Pablo VI (1971) Octogesima adveniens, n. 51. 